\title{
Migrações internas no Brasil: um panorama analítico e alguns percursos teóricos
}

\author{
Tiago Carlos Lima do Nascimento* \\ Ricardo Ojima**
}

BAENINGER, R. Fases e faces da migração em São Paulo. Campinas: Núcleo de

Estudos de População - Nepo/Unicamp, 2012.146p.

Como resultado das reflexões condensadas para o ensaio do concurso de livre-docência junto ao Departamento de Demografia da Unicamp, Rosana Baeninger reúne neste livro um panorama analítico que resgata os processos migratórios brasileiros em seus contextos econômico e social. O percurso teórico-metodológico desenvolvido na obra recupera a reconstrução histórica do fenômeno migratório e, a partir do pressuposto da centralidade paulista, busca construir tipos migratórios associados às etapas da dinâmica econômica brasileira, atrelados aos processos de mudanças sociais, estruturais e espaciais desde o século XVIII até o período atual.

Em Fases e faces da migração em São Paulo, Baeninger traz uma importante contribuição aos estudos populacionais, ao descrever e analisar os processos migratórios brasileiros a partir de uma perspectiva integrada e comprometida com diferentes escalas de análise, possibilitando relacionar os fenômenos migratórios em escala global dialeticamente com a escala local. Desse modo, são elaborados diálogos entre os fluxos migratórios internos e os internacionais no território brasileiro e, com base nestas análises, são elencadas novas categorias de estudo e conceitos que, por meio de desafios teóricos e metodológicos, auxiliam a compreender as migrações brasileiras no período atual.

Não se trata efetivamente de uma abordagem inovadora, pois há um reconhecimento por parte dos pesquisadores da área - e da própria autora - de que as migrações contemporâneas

\footnotetext{
*Universidade Federal do Rio Grande do Norte - UFRN, Caicó-RN, Brasil (tiago.tcln@gmail.com).

** Departamento de Demografia e Ciências Atuariais - DDCA, Universidade Federal do Rio Grande do Norte - UFRN, Caicó-RN, Brasil (ricardo.ojima@gmail.com).
} 
assumem características onde as categorias analíticas tradicionalmente usadas perdem fôlego. Talvez seja esta a principal contribuição da obra: abrir espaço para que, a partir de uma abordagem que busca a totalidade, se busquem novas formas de interpretar as migrações no Brasil.

Na primeira parte do livro - "Fases da migração" -, a autora procura reconstruir os fluxos migratórios históricos brasileiros e sua ligação com as relações de produção econômica que, comparados aos os fluxos de redistribuição populacional, apresentaram características historicamente distintas. Em “Migração: tipo e etapa”, Baeninger realiza uma análise da história migratória brasileira, relacionando-a com os processos sociais, econômicos e políticos. Tendo como ponto de partida meados do século XVIII, ela inicia sua abordagem passando pelo intenso crescimento demográfico e a dinâmica da divisão social do trabalho para chegar aos processos migratórios. Assim, partindo do contexto de exploração colonial e uma crescente economia voltada para a exportação, foram marcados ciclos nos diversos ramos produtivos, com a necessidade de ocupação de novas terras e de mão de obra nestes novos locais, alterando, desse modo, as bases geográficas da produção e da mobilidade populacional.

São apresentadas, então, as disparidades nos contingentes entre população livre e população escrava. Esta última sujeita à migração forçada para trabalhar nos latifúndios que desenvolviam a monocultura. A autora traz dados da quantidade de migrantes que vieram ao Brasil na condição de escravos e suas relações com os modos de produção locais dentro do contexto das migrações internas e sua realocação no território brasileiro para servirem como mão de obra.

Dando continuidade à sua análise, Baeninger discute a transição do uso da força de trabalho escrava para uma força de trabalho assalariada. Diante de contextos sociais e políticos, como a inibição à prática da escravatura e as políticas do Estado brasileiro em aumentar seu contingente populacional para suprir a necessidade de mão de obra, entra em pauta a discussão sobre os intensos fluxos migratórios internacionais em direção ao Brasil. Por meio de uma análise crítica que coloca em questão as relações de produção agrária brasileira, as relações políticas e as formas capitalistas de produção, a autora explicita como estes migrantes vieram ao Brasil para suprir a demanda por mão de obra barata deixada pelos escravos e a abertura de um novo mercado consumidor para esta nova população.

Assim, ela indica como se deu a participação desta população estrangeira dentro da população brasileira e seus efeitos diretos e indiretos nos modos de produção locais, principalmente para os fluxos migratórios internos, considerando que a expressiva presença de várias populações estrangeiras inibia a necessidade de uma mão de obra local, isto é, inibia os fluxos de migração interna no Brasil.

Desse modo, a autora elabora importantes análises sobre a intensidade dos fluxos de migrantes internacionais em direção ao Brasil, como eles se encaixavam nas relações locais de produção, as relações de trabalho desenvolvidas, sua distribuição dentro do território brasileiro e as especificidades dos grupos. A periodização elaborada nesta obra surge como uma importante abordagem demográfica para se compreender a formação do capitalismo no Brasil. 
Com a rediscussão de categorias de análise e tipologias já elaboradas, a autora avança no entendimento processual destes fluxos migratórios enquanto um conjunto de processos, movidos pela mesma lógica de produção capitalista, que nos permite analisar a expressiva diminuição dos fluxos migratórios internacionais e sua relação com o aumento dos fluxos migratórios internos no Brasil no período de sua urbanização.

A autora discorre sobre a diminuição da migração internacional em direção ao Brasil e a insurgente necessidade por mão de obra nos principais centros industriais que estavam despontando a partir da década de 1930. Considerando esse período como o início da configuração de um novo tipo migratório, Baeninger argumenta como os fluxos migratórios regionais ganharam fôlego, as desigualdades fomentadas pela implantação da agroindústria, as desigualdades regionais imanentes no território brasileiro e o intenso processo de industrialização concentrador que deu forma aos fluxos migratórios neste período, caracterizando principalmente as migrações do rural em direção ao urbano - em especial o Sudeste e seus polos de concentração industrial - e a migração do rural em direção ao rural, com a expansão das fronteiras agrícolas.

Elaborando uma discussão histórico-estruturalista, Baeninger discorre sobre os processos de transformação nas relações de produção, principalmente de ordem econômica, e como estas formas interagiram com os fluxos de população, especialmente na relação espacial entre o rural e o urbano, colocando em questão as formas de produção do campo, bem como os grandes centros urbanos e seu crescimento.

No subcapítulo intitulado "Migrações: modalidades migratórias e urbanização", são colocados em questão os fluxos migratórios recentes. As mudanças do período anterior ocorreram no início da década de 1980, quando os tradicionais centros começaram a diminuir seus saldos migratórios, reduzindo sua capacidade de atração populacional. Embasada numa ampla bibliografia, a autora aborda os processos de desconcentração das relações de produção econômica, trazendo uma série de dados por Unidades da Federação que nos permitem realizar esta leitura com facilidade. Assim, o diálogo é elaborado entre estas novas formas de produção desconcentradas e dispersas no território globalizado e as novas características das trocas populacionais do urbano em direção ao urbano e fluxos em direção a pequenas e médias cidades, que, por sua vez, adquirem novas formas e funções no período de desenvolvimento capitalista atual.

Em “Migrações, migrações”, a autora discorre sobre as relações entre os processos políticos, urbanos, econômicos e culturais no Brasil contemporâneo, para destacar a importância das análises multiescalares, isto é, como as diversas escalas espaciais permitem compreender o movimento migratório em sua complexidade no período da divisão social e territorial do trabalho no processo de reestruturação produtiva que vem modificando os processos migratórios e tornando-os mais complexos. No final desta primeira parte, a autora elabora uma releitura sobre o conceito de rotatividade e busca dar uma nova contribuição para o entendimento da mobilidade populacional no contexto da sociedade hodierna. 
Na segunda parte do livro, há um rico acervo fotográfico de material documental de migrantes locais, bem como fotos de famílias e pessoas que migraram para São Paulo. Nesse contexto, é apresentada a descrição das linhas temáticas de pesquisa do Observatório das Migrações em São Paulo.

Há ainda muito que se entender e novos elementos parecem demandar mais estudos no que se refere aos fluxos migratórios brasileiros. O livro aponta para tais desafios, mas não aprofunda essas novas formas de interpretação possíveis. De fato, há um reconhecimento implícito de grande parte dos pesquisadores da área de que tais transformações demandam a busca de novos paradigmas, entretanto, não parece haver ainda estudos sistemáticos que tenham atingido tais objetivos para apreender as migrações contemporâneas no Brasil. De certo modo, mais importante do que a busca por análises multiescalares, seria fundamental que as pesquisas na área pudessem convergir em análises multimétodos e transdisciplinares.

O desafio não é pequeno, mas com este livro temos uma revisão histórica dos fluxos migratórios brasileiros, com enfoque maior em São Paulo, que elabora uma periodização dos tipos de migração do período colonial até a atualidade e permite realizar uma leitura das migrações envolvendo o território brasileiro enquanto um processo de relações capitalistas contínuo. Por fim, mas não menos importante, é registrado um percurso teórico e metodológico com riqueza de contribuições conceituais para os estudos migratórios futuros e servirá, portanto, como um grande incentivo para que jovens pesquisadores adentrem pela seara dos estudos de migração no Brasil.

\section{Autores}

Tiago Carlos Lima do Nascimento é geógrafo e mestrando em demografia pelo Programa de Pósgraduação em Demografia - PPGDEM da Universidade Federal do Rio Grande do Norte - UFRN.

Ricardo Ojima é sociólogo e demógrafo. Professor do Departamento de Demografia e Ciências Atuariais - DDCA da Universidade Federal do Rio Grande do Norte - UFRN.

\section{Endereço de correspondência}

Ricardo Ojima

Universidade Federal do Rio Grande do Norte (UFRN)

Centro de Ciências Exatas e da Terra (CCET)

Departamento de Demografia e Ciências Atuariais (DDCA)

Avenida Salgado Filho, S/N, Lagoa Nova

Natal, RN - Brasil - CEP 59078-900

Recebido para publicação em 21/01/2014

Aceito para publicação em 03/03/2014 